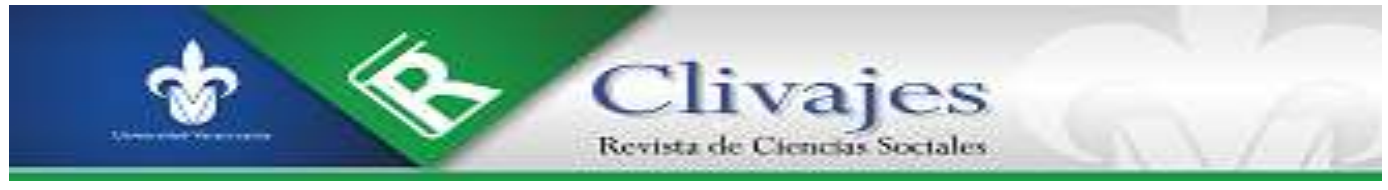

Ana Melisa Pardo Montaño

melisa.pardo@.comunidad.unam.mx

Instituto de Geografía de la Universidad Nacional Autónoma de México

SELECTIVIDAD Y DISCRIMINACIÓN: CATEGORÍAS DE ANÁLISIS PARA ENTENDER LOS PROCESOS MIGRATORIOS EN MÉXICO

DOI: https://doi.org/10.25009/clivajesrcs.i15.2691

Clivajes. Revista de Ciencias Sociales. Año VIII, número 15, enero-junio 2021, pp. 58-79.

https://clivajes.uv.mx/index.php/Clivajes

Instituto de Investigaciones Histórico-Sociales, Universidad Veracruzana

Clivajes. Revista de Ciencias Sociales/ISSN: 2395-9495/IIH-S, UV / Xalapa, Veracruz, México

Recibido: 24/03/2021

Aceptado: 14/04/2021

Dictaminado: 06/05/2021

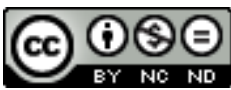

Clivajes. Revista de Ciencias Sociales (ISSN: 2395-9495), Año VIII, Núm. 15, enero-junio, 2021 Instituto de Investigaciones Histórico-Sociales, Universidad Veracruzana, México 


\title{
SELECTIVIDAD Y DISCRIMINACIÓN: CATEGORÍAS DE ANÁLISIS PARA ENTENDER LOS PROCESOS MIGRATORIOS EN MÉXICO
}

\author{
Ana Melisa Pardo Montaño*
}

\begin{abstract}
Resumen
Este artículo da cuenta de una investigación centrada en el análisis de dos categorías para comprender las actuales dinámicas de migración en México: la selectividad y la discriminación. La selectividad entendida a través del concepto de "nacionalidades privilegiadas" y la discriminación por medio de dos conceptos clave: "racialización” y "xenofobia". Para cumplir con este objetivo, se retoman datos de los Censos de Población y Vivienda, y de la Encuesta Intercensal, realizados en México por el INEGI (1990-2015). Se hace una revisión hemerográfica con énfasis en las categorías señaladas y se retoma testimonios de grupos de distintos colectivos en redes sociales, espacios virtuales donde se han publicado denuncias sobre el rechazo a esta población, así como datos del Instituto Nacional de Migración (INM) y entrevistas semiestructuradas a migrantes de tránsito y residentes en México.
\end{abstract}

Palabras clave: Migración, Discriminación, Xenofobia, Raza, México

SELECTIVITY AND DISCRIMINATION: ANALYSIS CATEGORIES TO UNDERSTAND MIGRATION PROCESSES IN MEXICO

\begin{abstract}
This paper focuses on the analysis of two categories to comprehend the current dynamics of immigration processes in Mexico: selectivity and discrimination. We study selectivity through the concept of "privileged nationalities" and discrimination through two key concepts "racialization" and "xenophobia". To achieve the proposed objective, we use data from Mexico's Population and Dwelling Census and the Intercensal Survey (1990-2015). We also carry out a revision of the hemerographic sources with an emphasis in the mentioned categories and we analyze testimonies from groups of different collectives in social networks, virtual spaces in which different complaints have been made rejecting this population, including the National Migration Institute and semi-structured interviews with transit migrants and residents in Mexico.
\end{abstract}

Keywords: Migration, Discrimination, Xenophobia, Race, Mexico

\section{SELECTIVITE ET DISCRIMINATION : CATEGORIES D’ANALYSE POUR COMPRENDRE LES PROCESSUS MIGRATOIRES AU MEXIQUE}

Résumé

Cet article rend compte d'une recherche centrée dans l'analyse de deux catégories pour comprendre les actuelles dynamiques de migration au Mexique : la sélectivité et la discrimination. La sélectivité comprise à travers le concept de «nationalités privilégiées » et la discrimination à travers deux concepts clés : «rationalisation » et «xénophobie ». Pour atteindre cet objectif, on reprend des données des Censos de Población y Vivienda, et de l'Encuesta Intercensal, réalisés au Mexique par l'INEGI (1990-2015). On fait une révision hémérographique en mettant l'emphase dans les catégories signalées et on reprend des témoignages de groupes de différents collectifs parmi des réseaux sociaux, des espaces virtuels où on a publié des dénonces sur le rejet envers cette population, ainsi que des données de l'Instituto Nacional de Migración (INM) et des entretiens semi structurés aux migrants de transit et résidents au Mexique.

Mots clés : Migration, Discrimination, Xénophobie, Race, Mexique

* Investigadora en el Instituto de Geografía de la UNAM y miembro del Sistema Nacional de Investigadores, es doctora en Geografía por la UNAM, maestra en Población y Desarrollo por la Facultad Latinoamericana de Ciencias Sociales (FLACSO), sede México, y licenciada en Ciencias Sociales por la Universidad del Valle en Cali, Colombia. Ha publicado libros y artículos sobre tema migratorio; entre ellos, Migración y transnacionalismo, extrañando la tierrita (2017, FLACSO) y Política Migratoria en México. Legislación, imaginarios y actores (2016, FLACSO, en coautoría con Cecilia Bobes).

Clivajes. Revista de Ciencias Sociales (ISSN: 2395-9495), Año VIII, Núm. 15, enero-junio, 2021 Instituto de Investigaciones Histórico-Sociales, Universidad Veracruzana, México 


\section{INTRODUCCIÓN $^{1}$}

Si bien el fenómeno migratorio ha estado presente en la historia de México, el estudio de los movimientos migratorios se ha enfocado principalmente en la expulsión de población hacia Estados Unidos, sin desconocer la enorme importancia que tienen para el país otros movimientos como el retorno, la migración interna, la inmigración, la migración de tránsito y el desplazamiento interno forzado. Estos dos últimos fenómenos se han hecho cada vez más notables, debido tanto a la violencia que sufre el país, como al incremento de los movimientos masivos de población en las "caravanas" de migrantes que han intentado cruzar el país para llegar a Estados Unidos y han dejado ver los vacíos jurídicos y de atención a los derechos humanos que existen en México.

Sobre la migración de tránsito a través de caravanas, los datos disponibles son principalmente los que ofrecen los medios de comunicación. Las más recientes que han difundido algunas fuentes periodísticas tuvieron origen en enero y junio de 2020. En la primera caravana viajaba, sobre todo, población procedente de El Salvador y Honduras, y de acuerdo con algunos medios, se movilizaban entre 2500 y 3000 personas. ${ }^{2}$ Una de las últimas registradas, procedente de Honduras, ${ }^{3}$ que contaba aproximadamente con cien personas, aunque tuvo menor difusión, llamó la atención de los medios porque sus integrantes buscaban cruzar la frontera entre Guatemala y México, aun en las actuales condiciones de la enfermedad Covid-19, que han frenado la movilidad de distinta manera.

Estos movimientos migratorios han logrado modificar de manera relevante la representación de la movilidad humana en el país, en particular porque la migración centroamericana se caracterizaba por contar cientos de personas (en su mayoría hombres) movilizándose en "La Bestia", hasta llegar a la frontera con EEUu e intentar cruzar al vecino país con apoyo de "coyotes". No obstante, las condiciones actuales de inseguridad, violencia y precariedad, entre otras causas, han dejado un escenario en donde familias completas, menores de edad sin acompañamiento, mujeres embarazadas, grupos lésbico-gay-transexual-bisexual-intersexual (LGTBI), entre muchos

\footnotetext{
1 Los resultados de investigación a los que alude este trabajo forman parte de los proyectos: Tryspaces (www.tryspaces.org), con financiamiento del Consejo de Investigación de Ciencias Sociales y Humanidades de Canadá, número de concesión 895-2017-1019, y "Espacialización de la violencia y migración internacional en contextos urbanos en México" (IN311319), del Programa de Apoyo a Proyectos de Investigación e Innovación Tecnológica PAPIIT, UNAM (2019-2020).

${ }^{2}$ Caravana de inmigrantes en México: ¿cómo es el flujo migratorio en la frontera y quiénes necesitan una visa para entrar a territorio mexicano? (2020, enero 20) Recuperado de https:// cnn.it/3wzx5HH.

3 Nueva caravana de migrantes hondureños parte rumbo a Estados Unidos (2020, junio 30). Recuperado de https://cnn.it/2Rmv7dx.

Clivajes. Revista de Ciencias Sociales (ISSN: 2395-9495), Año VIII, Núm. 15, enero-junio, 2021 Instituto de Investigaciones Histórico-Sociales, Universidad Veracruzana, México
} 
otros, buscan visibilizarse, pues resulta una estrategia más segura, dadas las circunstancias de violencia que enfrenta México. De igual manera, las dificultades para cruzar de México hacia Estados Unidos han propiciado que un grupo importante de estas personas soliciten una estancia regular en el país.

Estos elementos han derivado en que cada vez sea más evidente la presencia de población extranjera en México. Muchas organizaciones de la sociedad civil a lo largo del país han apoyado la presencia de migrantes y se han concentrado en atender las necesidades inmediatas de dicha población. Otros grupos se han enfocado en resaltar las problemáticas que puede desencadenar, para los nacionales, la llegada, supuestamente masiva, de personas centroamericanas y de otros países. Las muestras de recepción y rechazo son el interés principal del presente trabajo, cuyo objetivo fundamental es analizar algunos de los efectos que ha tenido la presencia de población extranjera en el país: la selectividad, analizada a través del concepto "nacionalidades privilegiadas", y la discriminación, agrupada en dos conceptos principales: "racialización de la migración" y "xenofobia”.

Considerando esto, la primera parte busca contextualizar estos tres conceptos; el propósito de la segunda parte es caracterizar la presencia de esta población en México, considerando los datos estadísticos disponibles, lo que permite mostrar que si bien la cantidad de extranjeros en el país no es tan cuantiosa como en otros movimientos migratorios, la diversidad de características de estos migrantes es un aspecto a tomar en consideración; la última parte busca resaltar cómo se presentan tanto la xenofobia como la racialización en México, mientras que ciertas nacionalidades que podemos considerar privilegiadas logran ingresar, insertarse y permanecer en el país con menores restricciones.

La información para la investigación proviene de los Censos de Población y Vivienda de México y de la Encuesta Intercensal elaborados por el INEGI (1990-2015), la revisión hemerográfica de noticias sobre el tema, algunos testimonios de distintos colectivos en redes sociales, espacios virtuales donde se han hecho denuncias sobre el rechazo de esta población, incluyendo la del Instituto Nacional de Migración ${ }^{4}$ y entrevistas semiestructuradas a migrantes de tránsito y residentes en México. Las entrevistas fueron realizadas a extranjeros residentes en México en las que se enfatiza

${ }^{4}$ Para este análisis, se tomaron en cuenta las redes sociales de algunos grupos de migrantes en México, albergues de atención a migrantes y el sitio del Instituto Nacional de Migración, que han sido espacios en los que tradicionalmente los migrantes expresan sus dudas y experiencias para ingresar al país.

Clivajes. Revista de Ciencias Sociales (ISSN: 2395-9495), Año VIII, Núm. 15, enero-junio, 2021 Instituto de Investigaciones Histórico-Sociales, Universidad Veracruzana, México 
en las causas de la migración y algunas situaciones de discriminación que han sufrido en el país durante su estancia.

\section{SELECTIVIDAD Y DISCRIMINACIÓN PARA ANALIZAR EL FENÓMENO MIGRATORIO}

Las dinámicas migratorias actuales a nivel mundial muestran distintas problemáticas que van desde la facilidad que ciertos grupos tienen para moverse en el espacio, como las dificultades que presentan otros. En este sentido, la xenofobia, la racialización de la migración y la selectividad de acuerdo con la nacionalidad de origen son aspectos que se han hecho cada vez más relevantes, en particular para el caso de México. A estos, incluso podría agregársele un cuarto: la aporofobia o miedo/desprecio al pobre, ya que la llegada reciente de ciertos grupos de migrantes al país ha generado resistencia en algunos sectores de la población, que se enfatiza por las condiciones económicas de estas poblaciones, el tipo de trabajos a los que aspiran e incluso el hecho de que, dada sus condiciones económicas, pueden llegar a convertirse en una carga para los países de destino.

Tanto la xenofobia como el racismo pueden considerarse fobias hacia personas determinadas, incluso sin conocerlas, solo por pertenecer a un grupo con características específicas, que resultan despreciables para quien experimenta el miedo o la fobia hacia ellas (Cortina, 2017). Como lo menciona esta misma autora, "Éste es un punto clave en el mundo de las fobias grupales: la convicción de que existe una relación de asimetría, de que la raza, etnia, orientación sexual, creencia religiosa o atea del que desprecia es superior a la de quien es objeto de su rechazo" (Cortina, 2017, p. 18).

Esta relación de asimetría se identifica con facilidad cuando hablamos de población migrante, la cual, por su condición de extranjera, de “extraña”, pero también en ocasiones por sus condiciones económicas, no suele ser tratada de la misma manera en los lugares de destino, independientemente de que su llegada tenga que ver con que quienes migran se hayan convertido en personas "no rentables" (Valverde, 2015) en su lugar de origen, principalmente porque son el excedente del sistema económico moderno (migrantes económicos) o porque su vida y la de sus familias corre peligro en los lugares de origen (refugiados o desplazados internacionales por violencia). Como bien menciona Bauman (2016), no se espera que en un futuro próximo estos flujos migratorios vayan a mermar, ni porque las condiciones económicas y políticas de los lugares de origen cambien, ni porque las políticas migratorias de los lugares de destino se hagan cada vez más restrictivas o se pongan en práctica otro tipo de ideas ingeniosas

Clivajes. Revista de Ciencias Sociales (ISSN: 2395-9495), Año VIII, Núm. 15, enero-junio, 2021 Instituto de Investigaciones Histórico-Sociales, Universidad Veracruzana, México 
para desaparecer estos movimientos. Esta idea de crecimiento del número de migrantes es uno de los factores que ha derivado en el rechazo hacia estas personas extranjeras y su constante presencia.

Si bien la migración internacional ha estado dirigida principalmente hacia países desarrollados, entre los que sobresalen, por ejemplo, Estados Unidos y algunos países europeos, recientemente la migración latinoamericana está tomando cada vez mayor relevancia en los movimientos intrarregionales, tal es el caso de países como México, Chile, Colombia, Venezuela, Argentina, entre otros (Pardo y Dávila, 2016). La presencia de estos movimientos migratorios se suele atribuir a los cambios en las políticas migratorias en destinos tradicionales y a las continuas crisis migratorias a nivel mundial, lo que ha obligado a la población a buscar destinos alternativos a los tradicionalmente elegidos por los migrantes en la región.

Existen diversas teorías que explican el fenómeno migratorio. Algunas refieren causas económicas para explicar los movimientos de población: la teoría de la economía neoclásica, la nueva economía de la migración, la teoría de los mercados duales de trabajo, la teoría del sistema mundial, entre otras, ${ }^{5} \sin$ desconocer que existen otras causas de la migración asociadas con aspectos políticos, de violencia, culturales, por mencionar algunos ejemplos. La presencia de diversas perspectivas para el análisis de las causas de la migración, tiene relación con que no existe una sola teoría que explique el fenómeno, dados los distintos aspectos vinculados con la migración. En particular, cuando se trata de migración económica, suele hacerse alusión a los movimientos de países pobres hacía países ricos, como menciona Collier (2014), quien, al igual que Bauman (2016), no considera que los flujos migratorios vayan a disminuir en los próximos años. De acuerdo con Collier (2014), varios elementos ayudan a explicar esto: El primer hecho es que la brecha salarial entre los países pobres y los ricos es brutalmente amplia y que el proceso de crecimiento global la mantendrá así durante algunas décadas. El segundo es que la inmigración no hará menguar significativamente esta brecha, porque los mecanismos de retroalimentación son demasiado débiles. El tercero es que, mientras la inmigración continúe, las diásporas seguirán acumulándose durante varias décadas. Así pues, la brecha salarial persistirá, mientras que el facilitador de la inmigración aumentará. Como consecuencia, la emigración desde los países pobres hacia los ricos tiende a acelerarse. En un futuro predecible, la inmigración

\footnotetext{
${ }^{5}$ Para indagar más sobre las distintas teorías que explican la migración, consultar Pardo (2015), Roldán (2012), Arango (2003) y Durand (2000).

Clivajes. Revista de Ciencias Sociales (ISSN: 2395-9495), Año VIII, Núm. 15, enero-junio, 2021 Instituto de Investigaciones Histórico-Sociales, Universidad Veracruzana, México
} 
internacional no alcanzará el equilibrio: hemos asistido a los comienzos de un desequilibrio de proporciones épicas (Collier, 2014, pp. 50-51).

Sin embargo, como se ha venido refiriendo, este crecimiento de la migración también suscita tanto rechazo hacia ciertos grupos con características particulares, como acogida hacia otros. Granado (2012) utiliza el concepto “paradoja demográfica”, para apuntar la interacción entre la necesidad de los países ricos de "importar trabajadores" para sostener su igualdad económica y el cierre de fronteras a migrantes de menor nivel socioeconómico, esto es que favorece el desplazamiento selectivo de las personas preparadas que no han logrado insertarse en el mercado laboral de su lugar de origen. No obstante, aunque este autor destaca el desplazamiento desde países en desarrollo hacia aquellos con economías más desarrolladas, lo que se observa en la actualidad es que esta migración selectiva sucede también entre países con economías similares, tal es el caso del auge de la migración intrarregional en América Latina.

En general, esta preferencia por los flujos migratorios con características específicas resalta la relativamente fácil y libre circulación de capitales y personas para ciertos fines, como el turismo y, en algunos casos, la migración por estilo de vida, pero también la restricción que tiene la migración por motivos económicos o el desplazamiento forzado por violencia

Esta migración no deseada suele ser percibida como peligrosa, por lo que está continuamente expuesta a la discriminación, la xenofobia y el racismo. Como lo explican Tijoux y Córdoba (2015), se trata de una visión histórica que ha mantenido a estos grupos atrapados en una especie de paradoja, donde el sistema neoliberal los requiere para seguir reproduciendo capital, pero los desecha cuando resultan una “carga” para el sistema mismo por su edad, estado de salud o porque en algunos lugares "quitan el empleo a los nacionales".

El racismo ha sido una de las principales bases para el rechazo y la discriminación de algunos grupos migratorios. En este sentido, las "teorías raciales" han referido las diferencias biológicas entre grupos humanos que han clasificado, identificado y jerarquizado ciertos grupos sociales, considerando que sólo por estas diferencias un grupo puede ser clasificado como superior frente a otro (Rojas, Amode y Vásquez, 2015). Por su parte, Balibar y Wallerstein (1991) explican el racismo como un fenómeno social que "se inscribe en prácticas (formas de violencia, de desprecio, de intolerancia, de humillación, de explotación), discursos y representaciones que son otros tantos desarrollos intelectuales del fantasma de profilaxis o de segregación (necesidad de purificar el cuerpo social, de preservar la identidad del 'yo', del 
'nosotros', ante cualquier perspectiva de promiscuidad, de mestizaje, de invasión), y que se articulan en torno a estigmas de la alteridad (apellido, color de la piel, prácticas religiosas)" (p. 31).

En la actualidad, desde ciertas miradas epistemológicas se cuestiona que se hable de racismo, enfatizando que no es posible argumentar diferencias biológicas entre grupos humanos. Sin necesidad de caer en aspectos que ya han sido mencionados en otros estudios y que competen más a la biología, cabe decir que probablemente el interés sobre el racismo se centra en las lógicas de exclusión y segregación hacia ciertos grupos de personas por su color de piel o pertenencia étnica. Esto también se ha analizado desde el concepto neorracismo, el cual se presenta como una variante del racismo tradicional y alude a formas directas e indirectas de rechazo a la población por su color de piel o su condición de migrante. Como señalan Rojas, Amode y Vásquez (2015), lo que permite una mirada cultural de estos racismos es continuar evidenciando formas de exclusión hacia grupos minoritarios y por lo tanto "diferentes" en sociedades que se autonombran "igualitarias".

En ocasiones, otras formas de exclusión pueden estar relacionadas con la nacionalidad de origen. En estos casos, mientras el país de nacimiento es motivo para relegar a algunas personas, también se observa que otras nacionalidades son bienvenidas. Desde el turismo residencial o la migración por estilo de vida, se les suele considerar como migrantes de privilegio. Este grupo, por su nacionalidad de origen y sus condiciones económicas, se encuentran en una situación más aventajada que quienes migran por cuestiones económicas. A diferencia de los migrantes económicos, poseen recursos políticos y sociales para participar activamente en actividades locales, regionales y nacionales (O’Reilly y Benson, 2009; Croucher, 2009).

En el caso de esta investigación, dado que no se trata sólo de turismo residencial o migrantes por estilo de vida, sino de grupos de personas que intentan entrar al país o solicitar permisos para residir como migrantes temporales o permanentes y que no suelen tener mayor inconveniente a su ingreso, los hemos agrupado como nacionalidades privilegiadas. En contraste con la migración por estilo de vida, no necesariamente se trata de población con mayores recursos económicos, simplemente la nacionalidad que portan es el factor que sobresale para facilitar su ingreso al país o el acceso a sus derechos como migrantes.

Un concepto que puede estar asociado con las diferencias entre migrantes económicos y las nacionalidades privilegiadas puede ser el estigma. De acuerdo con Goffman (1993), la estigmatización se produce cuando se percibe por otras personas 
alguna característica negativa (que puede estar asociada a las particularidades del lugar de origen) y que configura la forma como las personas se conciben a sí mismas. Este es un aspecto relevante, que permite identificar las formas en que el contexto de origen puede repercutir en las relaciones que la población extrajera desarrolla con la comunidad de destino, y en ocasiones se caracteriza por fenómenos como la xenofobia y la racialización de la migración.

En este contexto, la racialización y la xenofobia permiten entender los efectos que ha tenido la llegada de algunos grupos poblacionales a México, mientras que las nacionalidades privilegiadas muestran otros grupos que son bien recibidos y tienen mayores facilidades de incorporación al país. La información provista en la siguiente sección permite determinar las características de la población extranjera de México, lo que posibilita tener una idea de aquellos grupos que son excluidos y aquellos que tienen mayor acogida en el país.

\section{CARACTERÍsTICAS DE LA POBLACIÓN EXTRANJERA EN MÉXICO}

Si bien México no ha sido tradicionalmente un país de inmigrantes, es importante resaltar que en los últimos años se ha presentado un crecimiento gradual de la población extranjera que ingresa al país, como se observa en la tabla 1. También es necesario señalar que una de las particularidades de la inmigración es la multicausalidad. Si bien la pobreza en el país de origen es un factor detonante de la migración de muchas personas a México, la búsqueda de mejores condiciones educativas o salarios más altos también ha impulsado a grupos de inmigrantes a establecerse en el país (Pardo y Dávila, 2016). De igual manera, se ha presentado un importante crecimiento de población que en principio buscaba cruzar por México, con el objetivo final llegar a Estados Unidos, pero por distintas circunstancias ha decidido establecer su residencia permanente en México. Al mismo tiempo, la violencia extrema en otros lugares ha obligado a que algunas personas vean como opción cruzar por México para llegar a EEUU; en otros casos, dado que las actuales políticas migratorias de dicho país no les han permitido llegar a su destino, se han instalado en México como opción de destino final.

Este es el caso de los cubanos y haitianos en tránsito por México, quienes se habían instalado temporalmente en países de Sur y Centroamérica, aunque existe un grupo de personas de dichas nacionalidades que han entrado a México con documentación -como turistas o con residencia temporal-, para los cuales el tránsito 
por el país pudiera (o debiera) resultar menos complejo, y hay otro grupo que llegó de manera irregular (Garbey-Burey, 2017). ${ }^{6}$ Esta situación ha tenido eco a escala regional e internacional debido a la crisis humanitaria que generó, además de que trajo a la discusión el tema de la política de inmigración en países donde la recepción de población no ha sido muy común. Este ha sido el caso de Ecuador, Brasil o Chile, naciones a las que estos cubanos y haitianos (y recientemente incluso migrantes provenientes de África) llegaron originalmente, atravesando todo el continente, buscando entrar, como destino final, a los Estados Unidos.

Aunque, en comparación con la migración procedente de contextos como el centroamericano, la originaria de Cuba y Haití tiene cifras bajas, sus dificultades y vulnerabilidad son las mismas que padecen otros migrantes de tránsito por México, de modo que enfrentan, entre otras problemáticas, violación de sus derechos humanos, extorsión, secuestro y abuso por parte de las autoridades.

La importancia de otros grupos que se han ubicado en México también ha sido analizada. La mayoría de los estudios se centran en la migración procedente de Centroamérica, aunque muchos refieren a la migración de tránsito. Por mencionar algunos ejemplos sobre los centroamericanos residentes en México, Castillo y Vázquez (2010) presentan un recorrido histórico de su llegada, especialmente de la migración resultado de conflictos políticos, y algunos datos sobre la población inmigrante más reciente. Por su parte, Tinoco (2012) realiza un estudio que destaca el papel de las organizaciones civiles y la atención a la población centroamericana residente en México, para lo cual subraya la importancia numérica de esta población en los últimos años.

De acuerdo con el INEGI, en las últimas décadas, el número de extranjeros residentes en México se ha incrementado. Mientras en 1990 dicha población representaba $0.4 \%$ de la población total del país, en 2015 este porcentaje ascendió a $0.8 \%$, según datos de la encuesta intercensal, lo que equivale a poco más de un millón de personas extranjeras residiendo actualmente en México (Tabla 1). La mayoría de esta población procede de Estados Unidos, pero también un importante número de migrantes proviene de Centroamérica, Sudamérica y Europa.

\footnotetext{
${ }^{6}$ Como menciona la autora, entre las estrategias de migración irregular se encuentra el tránsito sin documentos como modalidad para ingresar, aludiendo tener nacionalidad cubana o de la República Democrática del Congo. 
Tabla 1. Extranjeros residentes en México, 1990-2015

\begin{tabular}{|c|c|c|c|c|c|c|c|c|}
\hline \multirow{2}{*}{ País } & \multicolumn{2}{|c|}{1990} & \multicolumn{2}{|c|}{2000} & \multicolumn{2}{|c|}{2010} & \multicolumn{2}{|c|}{2015} \\
\hline & Población & $\%$ & Población & $\%$ & Población & $\%$ & Población & $\%$ \\
\hline Total & 339780 & 100.00 & 519707 & 100.00 & 968271 & 100.00 & 1007063 & 100.00 \\
\hline Estados Unidos & 198230 & 58.34 & 358399 & 68.96 & 739918 & 76.42 & 739168 & 73.40 \\
\hline Guatemala & 42380 & 12.47 & 29156 & 5.61 & 31888 & 3.29 & 42874 & 4.26 \\
\hline España & 24620 & 7.25 & 21334 & 4.11 & 20727 & 2.14 & 22646 & 2.25 \\
\hline Colombia & 4660 & 1.37 & 6639 & 1.28 & 12832 & 1.33 & 18735 & 1.86 \\
\hline Venezuela & 1460 & 0.43 & 3024 & 0.58 & 10786 & 1.11 & 15664 & 1.56 \\
\hline Argentina & 4340 & 1.28 & 6625 & 1.27 & 14171 & 1.46 & 14747 & 1.46 \\
\hline Honduras & 1990 & 0.59 & 4203 & 0.81 & 9980 & 1.03 & 14544 & 1.44 \\
\hline Cuba & 2660 & 0.78 & 7267 & 1.40 & 11822 & 1.22 & 12768 & 1.27 \\
\hline El Salvador & 5060 & 1.49 & 5786 & 1.11 & 8864 & 0.92 & 10594 & 1.05 \\
\hline Canadá & 3100 & 0.91 & 7245 & 1.39 & 10208 & 1.05 & 9816 & 0.97 \\
\hline China & 1160 & 0.34 & 1847 & 0.36 & 7486 & 0.77 & 8860 & 0.88 \\
\hline Francia & 4190 & 1.23 & 5723 & 1.10 & 8533 & 0.88 & 8625 & 0.86 \\
\hline Italia & 3020 & 0.89 & 3761 & 0.72 & 5223 & 0.54 & 6406 & 0.64 \\
\hline Alemania & 4560 & 1.34 & 5632 & 1.08 & 7033 & 0.73 & 6400 & 0.64 \\
\hline Brasil & 1450 & 0.43 & 1887 & 0.36 & 4732 & 0.49 & 5832 & 0.58 \\
\hline Perú & 2570 & 0.76 & 3929 & 0.76 & 6870 & 0.71 & 5448 & 0.54 \\
\hline Chile & 2400 & 0.71 & 4846 & 0.93 & 5633 & 0.58 & 5160 & 0.51 \\
\hline Otro país & 31930 & 9.40 & 42404 & 8.16 & 51565 & 5.33 & 58776 & 5.84 \\
\hline
\end{tabular}

Fuente: Elaboración propia con base en datos del INEGI (1990, 2000, 2005 y 2015).

El mayor porcentaje de extranjeros en el país procede de Estados Unidos. El predominio de este grupo se suele atribuir a la fuerte presencia de personas nacidas en dicho país, pero cuyos padres son de origen mexicano y que por deportación o migración de retorno, entre muchas otras razones, han regresado a México, además de población jubilada procedente de Estados Unidos, la cual suele preferir retirarse a algunos estados mexicanos con climas agradables, ofertas culturales y acceso a amenidades de desarrollo, así como mercados de vivienda a bajo costo (Lizárraga, 2008). Este fenómeno ha sido estudiado a partir del concepto "turismo residencial". "migración por amenidades" o "migración por estilo de vida" (Aledo, 2008; Hidalgo et. al, 2009; Vergara et. al. 2019; Ceja, 2021).

En los últimos años también ha sido importante la llegada de personas procedentes de Sudamérica y el Caribe. En este grupo sobresalen aquellos que provienen de Colombia, Venezuela, Argentina y Cuba. Esta migración tiene entre sus casusas las políticas migratorias que han complicado la entrada de estos grupos a destinos tradicionales como Estados Unidos o países europeos. 
Según datos de 2015, en general, la población extranjera residente en México está compuesta por $50.4 \%$ de hombres y $49.6 \%$ de mujeres. Sin embargo, existen diferencias entre nacionalidades y regiones de origen. En el caso de la población procedente de Estados Unidos, predominan los hombres, mientras que los centroamericanos y sudamericanos tienen una mayor proporción de mujeres (85 hombres por cada 100 mujeres), exceptuando a los cubanos, salvadoreños y peruanos. En cambio, para los países asiáticos y europeos, la migración es predominantemente masculina, destacando China e Italia.

Cabe señalar también que si bien se trata principalmente de población joven (14 años como edad mediana, a diferencia de 27 de la población nacional), esta mayor presencia de jóvenes está asociada a la población proveniente de Estados Unidos (73.5\%, de acuerdo con los datos de INEGI en 2015), que - como ya se mencionó- en parte tiene ascendencia mexicana. Sin considerar este grupo, más de la mitad de la población migrante se encuentra en edades laborales $(60 \%$ se encuentra entre los 20 y 49 años).

En relación con el nivel de escolaridad, según datos de la encuesta intercensal de 2015, la población extranjera residente en México cuenta con una escolaridad mediana de 12 años y, en general, 45\% tiene licenciatura y más, aunque llama la atención que $15.7 \%$ sólo cuenta con primaria completa o menos. Si se analiza por zona de origen, existe una situación heterogénea. Los migrantes procedentes de Centroamérica son los que presentan mayores niveles de población sin escolaridad y primaria completa; especialmente los guatemaltecos, cuyo 78.2\% tiene primaria o menos. Los extranjeros oriundos de Sudamérica o Europa tienen la mayor escolaridad en conjunto, ya que más del 70\% de dicha población tiene licenciatura o más (con una escolaridad mediana de 16 años). Destacan los colombianos, venezolanos, peruanos y chilenos como los sudamericanos con más del 70\% de su población con licenciatura o más; en el caso de los europeos resaltan los franceses y alemanes con los mayores porcentajes de población altamente escolarizada.

En cuanto a las principales ocupaciones de los extranjeros en México, los datos de 2015 muestran, por ejemplo, que los centroamericanos se dedican principalmente a labores de agricultura, ganadería, silvicultura, caza y pesca, así como a actividades básicas y de apoyo. Los sudamericanos y europeos son principalmente profesionistas y técnicos o funcionarios, directores y jefes. En lo que respecta a los norteamericanos, éstos se ocupan, sobre todo, como profesionistas y técnicos o comerciantes, empleados en ventas y agentes de ventas.

Clivajes. Revista de Ciencias Sociales (ISSN: 2395-9495), Año VIII, Núm. 15, enero-junio, 2021 Instituto de Investigaciones Histórico-Sociales, Universidad Veracruzana, México 
Las características anteriores, especialmente la nacionalidad de origen, el nivel de escolaridad y la ocupación son aspectos que inciden en el lugar de residencia de los inmigrantes. Algunos extranjeros ingresan al país por cuestiones académicas o para incorporarse al mercado laboral más calificado, por lo que es común que intenten ubicarse cerca de los lugares donde llevan a cabo estas actividades. Aquellos que ingresan a laborar en la agricultura (en su mayoría provenientes de Guatemala), se ubican en estados de la frontera sur, primordialmente. Por otra parte, si bien con los datos censales no se puede observar, existen otros factores (políticos, sociales, culturales, etc.) que influyen en la ubicación residencial de los extranjeros en el país.

Tal es el caso de la población haitiana, pues un grupo considerable de nacidos en dicho país, que transitaron por México con la intención de llegar a EEuU, dadas las dificultades jurídicas para dicho ingreso, se han instalado en ciudades fronterizas, como Tijuana o Mexicali, donde sus intenciones de cruzar al vecino país se vieron frustradas, pero han logrado incorporarse al mercado laboral. Otros grupos que llegan con la intención de retirarse o jubilarse ubican sus residencias en zonas con climas amigables o donde ya hay redes de extranjeros asentados con anterioridad, como ocurre en Jalisco, lugares que además resultan económicamente rentables para inversiones económicas de estos grupos, que pueden adquirir viviendas a bajo costo.

Como se puede observar de acuerdo con los datos estadísticos, la población extranjera en México es diversa, pero a diferencia de otros países de la región con una mayor tradición inmigrante, en éste también se han diversificado en los últimos años las nacionalidades de origen y las causas por las que las y los migrantes permanecen en el país. Como se verá en el siguiente apartado, algunas de las características anteriores pueden contribuir a entender las problemáticas aquí abordadas en relación con el fenómeno migratorio: la discriminación, la xenofobia hacia algunos grupos vs. las facilidades que otros tienen para ingresar y permanecer en el país, debido principalmente a su nacionalidad.

\section{SELECTIVIDAD Y DISCRIMINACIÓN EN EL CONTEXTO MEXICANO}

Como afirman Smith y Guarnizo (2009), uno de los elementos a destacar del fenómeno migratorio a escala mundial es que las personas trasladan sus lugares de residencia a destinos en los que carecen de ciudadanía, lo que tiene distintas repercusiones, tanto en los modos de inserción a esos espacios (ubicación residencial, mercado laboral, etc.), como en las formas de participación democrática en términos reales. Esto ha llevado, 
en particular en el caso de México, a que los espacios de participación y de vida cotidiana se vean afectados directamente por cuestiones como la nacionalidad, que impacta en la forma como esta población logra reivindicar su origen, y en los modos como se incorpora a estos espacios de destino.

En general, en México se presenta cierta preferencia por flujos migratorios con algunas características en particular, lo que pone de relieve la relativa facilidad con la que circulan capitales o con la que se mueven algunas personas, como en el turismo, pero a la vez evidencia las restricciones para la circulación de personas que migran por razones económicas o de violencia. En este sentido, la política migratoria juega un papel relevante para entender las dinámicas que se presentan con el ingreso y la permanencia de ciertos grupos de extranjeros en el país. Si bien la Constitución Política de los Estados Unidos Mexicanos refiere la libre circulación de la población sin necesidad de requerimientos jurídicos ${ }^{7}$ (considerando, en todo caso, las restricciones que pongan las leyes de migración) y la Ley de Migración Mexicana, publicada en 2011, subraya el respeto irrestricto a los derechos humanos de todos los migrantes incluyendo nacionales de retorno y extranjeros, independientemente de su nacionalidad, origen o su situación migratoria, lo que se encuentra en muchas ocasiones es que son los agentes migratorios quienes deciden quién puede entrar y quién no, hecho que en muchas ocasiones ha derivado en quejas sobre el trato poco digno que reciben algunas personas al intentar ingresar al país.

Así podemos observar cómo en ocasiones el tema de la nacionalidad impacta desde la entrada al país, pues si bien muchas nacionalidades pueden entrar sin el requerimiento de una visa, ${ }^{8}$ la nacionalidad de origen es uno de los elementos que inciden en que los agentes migratorios decidan que una persona ingrese o no al país. Recientemente, esto sucede, primordialmente, con personas procedentes de Venezuela, Colombia y Perú, entre otros países:

Ayer, un amigo y su esposa embarazada llegaron al aeropuerto de la Ciudad de México. Son venezolanos y les negaron la entrada, los tuvieron más de 10 horas sin

${ }^{7}$ El artículo 11 menciona específicamente: "Toda persona tiene derecho para entrar en la República, salir de ella, viajar por su territorio y mudar de residencia, sin necesidad de carta de seguridad, pasaporte, salvoconducto u otros requisitos semejantes. El ejercicio de este derecho estará subordinado a las facultades de la autoridad judicial, en los casos de responsabilidad criminal o civil, y a las de la autoridad administrativa, por lo que toca a las limitaciones que impongan las leyes sobre emigración, inmigración y salubridad general de la República, o sobre extranjeros perniciosos residentes en el país. En caso de persecución, por motivos de orden político, toda persona tiene derecho de solicitar asilo; por causas de carácter humanitario se recibirá refugio. La ley regulará sus procedencias y excepciones".

8 Países y regiones que no requieren visa para viajar a México (2019, octubre 25). Recuperado de https://bit.ly/3mvvM7X.

Clivajes. Revista de Ciencias Sociales (ISSN: 2395-9495), Año VIII, Núm. 15, enero-junio, 2021 Instituto de Investigaciones Histórico-Sociales, Universidad Veracruzana, México 
agua ni comida e incomunicados. Traían la carta invitación mía y el personal del Instituto Nacional de Migración no respeta sus derechos humanos. Nunca me hablaron para confirmar los datos" (Mujer, opinión sobre el INM en página de Facebook; mayo, 2018).

Yo fui con todos esos requisitos y aun así me retuvieron y me devolvieron con una alerta migratoria; la chica que me atendió me pidió todos los papeles, me hizo las preguntas correspondientes, pero ni siquiera me escuchó, sólo hizo todo por protocolo. Me devolvió los papeles, me retuvieron 16 horas y me hicieron firmar un acta donde decía que yo no tenía claro el motivo de mi viaje y no sabía dónde me iba a hospedar, siendo que todo eso se lo expliqué y enseñé con pruebas. Le dije que por qué decía eso y me dijo, textualmente, el chico que se hacían muchas entrevistas y que por eso se confundían, que si no quería pasar más tiempo simplemente firmara y me devolvían (Hombre, página de Venezolanos en México, Facebook; febrero, 2020).

La primera vez intenté ingresar con toda la documentación: carta de invitación, dirección donde me iba a quedar, itinerario, en fin. Sin ninguna explicación ni preguntarme nada, me sacaron de la fila y me llevaron a otro lado, no me respondían lo que preguntaba. Aunque no dicen nada, uno se da cuenta que tiene que ver con la nacionalidad cuando te encierran con otro grupo de venezolanos a los que no nos explican nada, solo nos tratan muy mal y, al final, nos regresaron a todos. Lo volví a intentar una segunda vez pasado un año más o menos y aunque me preguntaron muchas cosas, al final sí logré entrar (Hombre, venezolano, entrevista realizada en febrero, 2017).

Como se puede observar, en los últimos años se han hecho varios reportes tanto en redes sociales como en distintos medios de comunicación, donde se manifiesta, como una de las principales problemáticas que sufre la población extranjera que intenta ingresar a México, la discrecionalidad por nacionalidad, por parte de los agentes migratorios, para decidir quién ingresa y quién no al país. Las respuestas por parte del INM enfatizan, sobre todo, la falta de documentación de algunas de las personas que intentan ingresar, aunque, por lo general, los reportes señalan que los extranjeros devueltos ingresan, en su mayoría, con toda la información necesaria. Incluso, en los grupos de Facebook y otras redes sociales, se ha hecho mención de las dificultades para ingresar, subrayando, en particular, aquella documentación (incluyendo dinero) que deberían portar migrantes de ciertas nacionalidades (colombianos y venezolanos, principalmente).

Al respecto, Arredondo (2005) señala que la internación restringida para algunas nacionalidades de manera discrecional se ha dado en México desde hace mucho tiempo, 
aunque estas disposiciones cambian día con día, al igual que las nacionalidades agrupadas como restringidas. El autor señala como nacionalidades restringidas la cubana, la colombiana, la china, la iraní y la norcoreana, entre otras que se mantienen en la actualidad; por ejemplo, en cuanto a la población colombiana, según los datos de la Embajada de Colombia en México, entre 2012 y 2016 se reportaron un total de 96 casos de ciudadanos colombianos ${ }^{9}$ que, aun con la documentación necesaria para ingresar al país, fueron devueltos por las autoridades migratorias sin ninguna justificación.

Quise exponer el caso de mi hija debido a la angustia que vivimos. Yo lo llamé un secuestro legalizado, al ser retenida e inadmitida en México. El caso no es que haya sido inadmitida, sino la angustia que padecimos por las condiciones en las que la tuvieron. Esto es algo inaudito que en este siglo se estén presentado la violación a los derechos humanos. Quisiera que eso no le pase a nadie más, quisiera que las autoridades mexicanas tomaran medidas con respecto a eso (Entrevista publicada por El tiempo, octubre, 2019).

No obstante, el problema no sólo tiene relación con la entrada al país, sino con la percepción o el imaginario sobre la población procedente de una nacionalidad restringida, asociada a la criminalidad o la prostitución que, en ocasiones, se ha atribuido a una cuestión cultural (Stang y Stefoni, 2016).

En general siento que se refieren a los colombianos como que andamos en malos pasos, incluso ahora con el tema de los prestamistas se ha puesto peor, porque, aunque son una minoría, uno siempre escucha cosas muy feas, de que no deberíamos estar aquí o cosas similares... Cuando veo noticias sobre eso y leo los comentarios que pone la gente, me molesta mucho, porque siempre dicen que no deberían admitir a colombianos o sacarnos a todos (Mujer colombiana residente en México, 2014).

Si bien la nacionalidad es un factor que explica la discriminación hacia la población migrante, desde la perspectiva de Granado (2012) -antes citado-, la aceptación selectiva de grupos específicos que pueden ser considerados benéficos para los lugares de origen, podría estar asociada no solo con aspectos económicos o de nacionalidad de origen, sino incluso de raza. En ocasiones, la nacionalidad pasa a un

\footnotetext{
${ }_{9}^{9}$ Estos son sólo los casos reportados por los colombianos en su respectiva embajada; sin embargo, existen cientos de denuncias en redes sociales, donde se menciona que diariamente ocurre esto con la población colombiana (y más recientemente venezolana). De acuerdo con un reportaje de El tiempo, en entrevista realizada a Luis Oswaldo Parada, cónsul de Colombia en México, en los últimos siete años han sido inadmitidas más de 16 mil personas de origen colombiano. Reportaje completo disponible en https://bit.ly/3sN7Q1J.
}

Clivajes. Revista de Ciencias Sociales (ISSN: 2395-9495), Año VIII, Núm. 15, enero-junio, 2021 Instituto de Investigaciones Histórico-Sociales, Universidad Veracruzana, México 
segundo plano, como indica Tanya Duarte (2020) en el informe sobre Detención migratoria y deportación de nacionales indígenas y afrodescendientes por el Instituto Nacional de Migración. En dicho reporte, la directora del Proyecto "Afrodescendencia México" señala: "Desde los veinte años aprendí que debo traer mi acta de nacimiento, pasaporte y todas las identificaciones posibles... Las autoridades del Instituto Nacional de Migración a menudo me dicen que mi INE (credencial para votar) es falsa... Los constantes interrogatorios por parte de los agentes de migración son parte de mi vida cotidiana como mujer afromexicana" (IMUMI, 2020). En el caso de los extranjeros en el país, a las características físicas se suma la nacionalidad, lo que implica en ocasiones una doble discriminación, como lo muestran algunos de los testimonios presentados en este trabajo.

Otro ejemplo que ilustra la importancia de la raza al referirse al tema migratorio en México, es el reporte del caso de dieciocho ciudadanos peruanos que intentaron realizar una escala en México antes de llegar a su destino en China: los agentes migratorios, en el aeropuerto, decidieron regresarlos. La noticia fue difundida por los medios de comunicación, que incluso entrevistaron a algunos de los afectados; uno de ellos declaró:

Hemos llegado a las 6:30 a México y a las 8:30 nos retornaron. Les decimos ¿por qué?... Porque no tienes pinta de turista; o sea, ¿tengo que tener qué pinta para hacer turismo en México? (Hermenegildo Mamani, entrevista publicada por El comercio, abril, 2018).

Esta discriminación por cuestiones raciales o de color de piel ha sido incluso subrayada por la ONU, institución que ha manifestado en varias ocasiones su rechazo a la discriminación hacia la población migrante e indígena ${ }^{10}$ en México, lo que refleja la importancia de esta problemática que se ha visibilizado nacional e internacionalmente. De acuerdo con Goffman (1993), esta discriminación genera estereotipos que terminan por estigmatizar a ciertos grupos considerados "los otros", por poseer características diferentes, y en el caso señalado, aunque se trate incluso de individuos que cuentan con la nacionalidad mexicana, sus características raciales, los convierten en sujetos discriminados.

En ocasiones esta discriminación también se da por el imaginario social sobre ciertos grupos de migrantes; es el caso de los centroamericanos, a quienes se asocia

\footnotetext{
${ }^{10}$ La ONU mostró su preocupación por la discriminación a indígenas y el uso excesivo de la fuerza contra migrantes en México (2019, septiembre 6). Recuperado de https: / /bit.ly/3wFCDAo.

Clivajes. Revista de Ciencias Sociales (ISSN: 2395-9495), Año VIII, Núm. 15, enero-junio, 2021 Instituto de Investigaciones Histórico-Sociales, Universidad Veracruzana, México
} 
particularmente con comunidades indígenas, de escasos recursos y que transitan por el país con el objeto de llegar a Estados Unidos, por lo que una alternativa para evitar este tipo de actitudes es imitar algunos aspectos característicos del lugar donde transitan como el acento:

Pues en principio no me creen que soy de El Salvador... De hecho, ya cambie mi acento, por lo mismo; al principio sí sufrí mucho bullying por lo mismo, o sea, está así cañón... La primera impresión dan de decir no creo que ese sea salvadoreño, epor qué? Por su acento o porque piensa que los salvadoreños somos chaparros, negritos y panzones, no sé, así pensaban al principio que eran los salvadoreños. De hecho, una vez en una fiesta de Halloween me dijeron: "no manches, ¿eres salvadoreño?" Sí, les dije, y ahí es donde me dijeron: "no, pues yo los hacia chaparros y negros" (Hombre, salvadoreño, entrevista realizada en 2017).

El tema de la discriminación por nacionalidad o raza, o por el imaginario que se tiene sobre la población de algunos países, no sólo afecta a aquellos que intentan cruzar por el territorio mexicano - como en el caso recién mencionado de los migrantes peruanos-, también perjudica a algunos residentes:

Aquí nos discriminan mucho, nos dicen que nosotros somos, que nosotros traemos mala influencia, que somos de las Maras y así; a mi mamá en el trabajo le pasaba todo el tiempo. Sólo porque veníamos de El Salvador, ya nos decían que éramos de las Maras (Mujer salvadoreña residente en México, 2017).

Creo que el problema es porque me ven negro, por eso siempre me están preguntando cosas cuando voy a entrar al país, no importa cuántos años lleve aquí. (Hombre colombiano residente en México, 2014).

En contraste, hay otros grupos de migrantes, provenientes de países europeos o de Estados Unidos, para quienes ingresar al país suele ser menos problemático, incluso si manifiestan que van a permanecer varios meses en este destino. A estos grupos se les ha denominado "nacionalidades privilegiadas". Si bien, para el caso de México, la nacionalidad de origen es uno de los principales factores para identificar a quienes tienen mayores oportunidades de ingreso y permanencia en el país, este llamado "privilegio" puede identificarse por las condiciones económicas, así como por el estatus migratorio con el que ingresan. Esto les permite participar en la vida social, económica y política en el destino, a diferencia de los migrantes económicos, a quienes en repetidas ocasiones se les cuestiona cualquier intento de participación (principalmente

Clivajes. Revista de Ciencias Sociales (ISSN: 2395-9495), Año VIII, Núm. 15, enero-junio, 2021 Instituto de Investigaciones Histórico-Sociales, Universidad Veracruzana, México 
política), a partir del Artículo 33 de la Constitución Política de los Estados Unidos Mexicanos. ${ }^{11}$

La presencia de esta población reconfigura el espacio y las dinámicas propias de los lugares donde se insertan. En el caso de México existen varios lugares donde es común hallar grupos de estadounidenses o canadienses que han encontrado nichos específicos donde habitar. Lizárraga (2008) menciona, por ejemplo, que existe un importante grupo de población, proveniente de Estados Unidos, que vive en Cabo San Lucas (Baja California); dicho grupo ha encontrado, en esta zona, un lugar donde retirarse, comprando viviendas a bajo costo y en un clima que les resulta agradable. Sin embargo, como bien afirma el mismo autor, las únicas empresas beneficiadas con la llegada de esta población son las inmobiliarias, que han fragmentado el espacio para construir viviendas acordes a las necesidades de este grupo, y ello ha derivado en el desplazamiento de la población local, pues los precios de la vivienda están pensados específicamente para estos extranjeros.

\section{CONSIDERACIONES FINALES}

De acuerdo con la ley migratoria mexicana, las personas que transitan y residen en México cuentan con todos los derechos humanos que garantiza la Constitución Política Mexicana sin distinción de nacionalidad, color de piel, idioma o cualquier otra característica, por lo que la libre circulación en el territorio y la no criminalización de esta población estarían garantizados para todos los extranjeros en el país, al menos en el discurso oficial (Bobes, 2018); no obstante, lo que se observa en la práctica es que esta circulación está limitada por distintas particularidades de los grupos de extranjeros que intentan ingresar, transitar y/o residir en el país. Si bien el interés de este trabajo no se centra en el análisis de la política migratoria del país, este elemento se debe tener presente para comprender en qué consisten y como funcionan la selectividad y la discriminación en los procesos migratorios; pero si consideramos que en México la población extranjera nacionalizada o los hijos de mexicanos nacidos en otros países no cuentan con todos los derechos que tiene una persona nacida en el país.

Las categorías para el análisis de la inmigración en México que aquí se presentan: selectividad y xenofobia, dan un panorama general de las problemáticas que enfrentan los extranjeros en el país. La noción del extranjero como el "extraño" del que hay que

11 El Art. 33 constitucional refiere la prohibición, dirigida a los extranjeros, a "inmiscuirse en los asuntos políticos del país. El artículo completo está disponible en: https://bit.ly/3EJOz6V.

Clivajes. Revista de Ciencias Sociales (ISSN: 2395-9495), Año VIII, Núm. 15, enero-junio, 2021 Instituto de Investigaciones Histórico-Sociales, Universidad Veracruzana, México 
cuidarse ha permeado no sólo en los discursos oficiales, sino, en general, en la cotidianidad de quienes viven en México, lo que ha derivado en la discriminación hacia distintos grupos de migrantes. Las motivaciones más recientes para dicha discriminación están asociadas con los discursos implementados en los últimos años en Estados Unidos, lo que ha obligado a que México tome medidas mucho más severas para la contención de la migración, principalmente por la dependencia económica con el vecino país. Todo esto a consecuencia de que el fenómeno migratorio sea considerado un tema de seguridad nacional.

No obstante, esta discriminación no ocurre sólo a nivel institucional, sino que el discurso también ha llegado a la población residente, que los replica después de escuchar en distintos medios de comunicación cómo la llegada de extranjeros "puede ser perjudicial para la economía”, pues ocuparán servicios básicos (salud, trabajo, educación, etc.), escasos incluso para los nacionales. Sin embargo, la inversión extranjera, la compra de viviendas y otras actividades similares de extranjeros provenientes de ciertas nacionalidades, que ingresan con recursos económicos, son vistas con naturalidad. Esto muestra que el principal problema no es el flujo de capital, sino el de personas. Aunque estas muestras de discriminación no son por parte de toda la población, impactan en la percepción que en ocasiones se tiene sobre México como país de recepción de migrantes.

La ambigüedad de la política migratoria en México, que permite la discrecionalidad de los agentes migratorios, quienes finalmente toman las decisiones en relación con el ingreso al país, es uno de los principales problemas a resolver. Si bien el país es uno de los pocos de la región que cuenta con una ley de migración y distintos programas y políticas al respecto, éstos resultan ineficientes e insuficientes, principalmente porque "una cosa es lo que dice la ley y otra cómo se aplica”. Esto hace necesario que, en aras de disminuir este tipo de diferencias para con los migrantes que ingresan al país, realmente exista claridad en la forma como se aplica la normativa vigente.

\section{REFERENCIAS}

AlEDO, A. (2008). De la tierra al suelo: la transformación del paisaje y el nuevo turismo residencial. ARBOR. Ciencia, Pensamiento y Cultura, 729, 99-113. 
ARANGO, J. (2003). La explicación teórica de las migraciones: luz y sombra. Migración y desarrollo, 1, 1-30.

Arredondo, F. (2005). Internación y legal estancia de los extranjeros en México. Revista Mexicana de Derecho, 7, 65-117.

Balibar, E., Y WALLERSTEIN, I. (1991). Raza, nación y clase. Lepala.

Bauman, Z. (2016). Extraños llamando a la puerta. Paidós.

Bobes, C. (2018). Migrantes de tránsito: (des) protección, exclusión y (no) acceso a derechos. En Bobes, C. (Ed.), Política migratoria y derechos de los migrantes en México (pp. 83-125). Facultad Latinoamericana de Ciencias Sociales.

CAstillo, M., Y VÁzQueZ, M. (2010). Los inmigrantes guatemaltecos en México: Antecedentes históricos y situación actual. En Rodríguez, E. (coord.), Extranjeros en México. Continuidades y aproximaciones (pp. 237-273). INM, Centro de Estudios Migratorios, DGE Ediciones.

CejA, M. (2021). Migración internacional de retiro: imaginarios sociales, memoria y cambios en el espacio de Ajijic. Revista IUS, 15(47), 343-376.

Collier, P. (2014). Exodus: Immigration and Multiculturalism in the 21 st Century. Edición de Penguin.

Cortina, A. (2017). Aporofobia, el rechazo al pobre. Un desafío para la democracia. Paidós.

Croucher, S. (2009). The other side of the fence. American migrants in Mexico. University of Texas Press.

DuRAND, J. (2000). Origen es destino. Redes sociales, desarrollo histórico y escenarios contemporáneos. En Tuiran, R. (coord.), Migración México-Estados Unidos. Opciones de política (pp. 249-262). Consejo Nacional de Población.

Goffman, E. (1993). Estigma. La identidad deteriorada. Amorrortu.

Granado, V. (2012). ¿Derecho de fuga? Derecho de migración y nacionalidad cosmopolita. ARBOR. Ciencia, Pensamiento y Cultura, 755, 489-502.

Hidalgo, R., Borsdorf, A., y PlazA, F. (2009). Parcelas de agrado alrededor de Santiago y Valparaíso: ¿Migración por amenidad a la chilena? Revista de Geografía Norte Grande, 44, 93-112.

IMUMI. (2020). Because of the Color of My Skin and the Way I Speak Spanish: The INM's Detention and Deportation of Indigenous and Afro-Descendant Mexicans, Instituto para las Mujeres en la Migración. Recuperado de https: / / bit.ly/30n753q.

LizÁrRaga Morales, O. (2008). La inmigración de jubilados estadounidenses en México y sus prácticas transnacionales: Estudio de caso en Mazatlán, Sinaloa y Cabo San Lucas, Baja California Sur. Migración y desarrollo, 11, 97-117. 
O’Reilly, K. y Benson, M. (2009). Lifestyle Migration. Escaping to the Good Life? En Benson, M. y O’Reilly, K. (Eds.). Lifestyle Migration. Expectations, Aspirations and Experiences (pp. 1-14). Ashgate.

PArís, M., Y MONTES, V. (2020). Visibilidad como estrategia de movilidad: el éxodo centroamericano en México (2018-2019). Entre Diversidades: Revista de Ciencias Sociales y Humanidades, 1, 9-38.

Rojas Pedemonte, N., Amode, N. y VÁsquez Rencoret, J. (2015). Racismo y matrices de "inclusión" de la migración haitiana en Chile: elementos conceptuales y contextuales para la discusión. Polis Revista Latinoamericana, 42, 1-23. Recuperado de https: / / bit.ly/3sXJjYl.

RoldÁn, G. (2012). Una aportación ignorada de la teoría neoclásica al estudio de la migración laboral. Migración y Desarrollo, 19, 61-91.

Smith, M. P., y GuARnizO, L. E. (2009). Global mobility, shifting borders and urban citizenship. Tijdschrift voor economische en sociale geografie, 5, 610-622.

StAnG, F., Y STEFOni, C. (2016). La microfísica de las fronteras. Criminalización, racialización y expulsabilidad de los migrantes colombianos en Antofagasta. Astrolabio Nueva Época: Revista digital del Centro de Investigaciones y Estudios sobre Cultura y sociedad, 17, 42-80.

Tijoux, M. E., y Córdova Rivera, M. G. (2015). Racismo en Chile: colonialismo, nacionalismo, capitalismo. Polis Revista Latinoamericana, 42, 7-13.

Tinoco, A. (2012). Entre exclusiones e inclusiones: procesos de inserción social de migrantes centroamericanos en el Valle de México. Tesis de Maestría. Facultad Latinoamericana de Ciencias Sociales.

Vergara, L., SÁnchez, C., y Zunino, H. M. (2019). Migración por estilo de vida: ¿Creando comunidades diversas y cohesionadas? El caso de Los Riscos, Pucón, Chile. Revista Austral de Ciencias Sociales, 36, 47-67.

VAlverde, C. (2015). De la necropolítica Neoliberal a la empatía radical. Violencia discreta, cuerpos excluidos y repolitización. Icaria. 